\title{
Conceptualization of Aviation Cabin Crew's Fatigue Risk Assessment
}

\author{
Irem Çevik ${ }^{1}$, Bibek Bam, Ajantha Dahanayake and Kalle Elfvengren \\ School of Engineering Science, Lappeenranta-Lahti University of Technology, \\ Lappeenranta, Finland
}

\begin{abstract}
Airlines are of great importance to the transportation sector. With the increase in commercial air travel, airlines require extra flight crews. Aviation industry's cabin crewmembers are faced with working overtime, working in shifts and long working hours. The shift system causes fatigue for flight crews. Fatigue is of critical importance in the aviation industry. Depending on the physical and psychological fatigue, explicit or implicit results appear. There are a number of approaches in the aviation industry to prevent fatigue. When previous studies are examined, there are few studies examine in the general, and aviation crew's fatigue treat both pilots and cabin crew alike. The relationship between cabin crew's fatigue-to-fatigue risk management systems, key fatigue-causing factors, tools to alarm fatigue, and outcome assessments are non-existent. However, various difficulties are encountered in measuring the cabin crews fatigue levels and measurements and are often subjective and not reliable. Therefore, the aim of this study is to create a concept map to be integrated into the aviation cabin crew's fatigue risk assessment application design and implementation in order to arrive at a comprehensive fatigue risk assessment tool for the aviation industry.
\end{abstract}

Keywords. Fatigue, Airline Cabin Crew, Fatigue Risk Management System, FRMS, Fatigue Assessment, Fatigue Assessment Tools

\section{Introduction}

Fatigue is among the workplace hazards that affect employee health and safety [1]. The International Civil Aviation Organization (ICAO) defines fatigue as "A physiological state of diminished mental or physical performance potential, from a sleep loss, extended alertness, circadian phase, and / or workload relating to mental and / or physical activity that can damage a person's alertness and capability to appropriately perform safety related operational duties [2].

Fatigue affects the aviation industry as well as all business areas. As one of the safest transport routes, the aviation industry needs to actively manage the hazards that affect safety [1][3]. Various organizations have made some recommendations for fatigue management. Flight duty time limitations (FTL) are officially released by international authorities in order to reduce and control risk of fatigue. Similarly, some guidelines are published by ICAO to support and contribute to the aviation industry. New rules have also been proposed by the Federal Aviation Administration (FAA) and the European Aviation Safety Agency (EASA) [2][4].

\footnotetext{
${ }^{1}$ Corresponding Author, İrem Çevik, School of Engineering Science, Lappeenranta-Lahti University of Technology, Lappeenranta, Finland; E-mail: irem.cevik@student.lut.fi
} 
More than $70 \%$ of aviation accidents are caused by human errors [5]. Various accidents in the aviation world have defined fatigue-related factors as one of the main causes of aviation accidents. With 24/7 flight operations, pilot and flight crew surveys show that fatigue is an important problem and causes at least 4-8\% setbacks in this sector [6].

There are many factors that cause fatigue, including social and family situations leading to sleep and circadian processes affecting sleep propensity and alertness [6][7]. Although cabin crew and pilots are evaluated in a similar way within the aviation sector, work and workload varies significantly between cabin crew and pilots. While the main workload of a pilot is the take-off and landing stages, the workload of the cabin crew continues during the flight. The fatigue risk related to cabin crew has not gained the needed attention in research [8].

In this context, this research pays attention to examine the fatigue risk management of aviation cabin crews. This research explores Fatigue and Fatigue Risk Management System (FRMS) in aviation sector, effects of fatigue and types of risks it creates for cabin crews, strategies and approaches available for reducing the cabin crew fatigue, and models available for fatigue assessment in flight crew (pilots and cabin crew). Finally, this research presents a fatigue assessment model specifically developed for fatigue risk management of aviation cabin crew. Figure 1 describes briefly the research approach followed in this research.

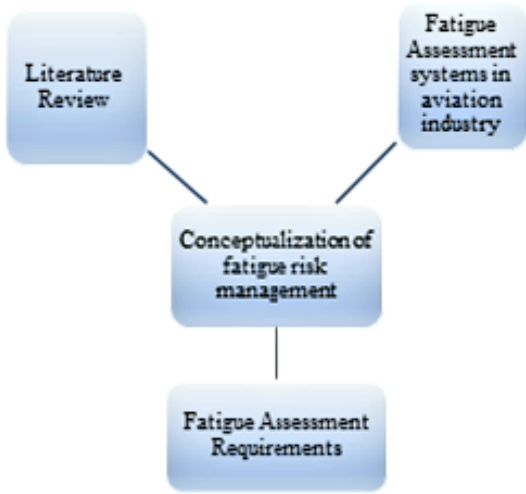

Figure 1: Research method

\section{Related studies}

\subsection{Definition of fatigue}

Fatigue is a state of feeling which can be physical, mental or both and it is considered as a warning that a person is not able to characterize but feels lackadaisical, exhausted, and tired. It is considered as the lack of energy and motivation in individuals and is not able to perform activities during work. It is described as the need for sleep. Fatigue can also include shortness of breath and weakness in muscles. It is considered as a complaint and it is necessary for an individual to consider fatigue as a symptom and it 
is not a disease. In complaint of fatigue, many illnesses can result, as it is a symptom of many diseases [2][15].

\subsection{Types and factors of fatigue}

Fatigue encompasses a variety of factors which are lifestyle-related factors, physical health conditions, and mental health problems. The lifestyle of fatigue includes experiencing fatigue because of activities like physical exertion, lack of physical activities, boredom, emotional stress, overweight, and using alcohol on regular basis. Mental health conditions also lead to fatigue and the common symptoms of fatigue are anxiety, depression and seasonal affective disorder [3][13][14]. These factors of fatigue result in not enough sleep, sleep apnea, depression, overloaded caffeine, and diabetes as some common examples.

Fatigue can affect people in different ways. During cognitive activities that require work efficiency, it may show its effect in the form of lack of motivation, inability to complete an activity, sleepiness, muscle weakness, etc. It is thought that the cause of fatigue may be in various forms depending on the nature. Fatigue can be classified as mental and physical fatigue [5][6][9][14].

Mental fatigue is associated with stress and other emotional experiences. It can make people feel mentally exhausted. It affects cognitive performance. In addition, sleep deprivation and other health factors affect mental fatigue [9][29]. It can show up itself in several ways as decrease in awakening or the level of commitment to the task at hand. Mental fatigue symptoms include the physical as well as emotional symptoms. The emotional signs are stress, depression, anxiety, emotionlessness, dread feeling, lack of motivation, difficulty concentrating and hopelessness feeling [9][14].

Physical signs include body aches, stomachaches, change in appetite, loss or gain of weight, increase in illness. Physical Fatigue is also muscle fatigue. It includes the physical inability of muscles that are not able to perform optimally for a temporary period [28]. It depends on the level of individual's physical fitness [27]. When an individual is not able to perform the task and continue the work, it is a symptom of fatigue. The most common symptoms include mental disorders, lack of motivation, irritability, eating disorder, stress or loss of appetite and insomnia [14][28].

\subsection{Effects of fatigue}

Fatigue effects in many different ways at the workplace, it affects employee in a negative way. Fatigue has an effect on physical and cognitive functions of an individual. The fatigue progression is continuous and involves important physiological changes that occur before and during mechanical failure. Cognitive function disorder is a growing public health problem. Physical exercise is known to be good for health and helps to reduce the risk of many cardiovascular and lung diseases [6][10][14].

In the transport industry like aviation, moving heavy items during flights cause physical as well as mental fatigue to an individual. It impacts on the work performed, because of fatigue and productivity can decrease. Continuous working times cause fatigue as well as working in night shift or working overtime hours may decrease work performance. Insufficient sleep can lead to a decline in productivity. In fact, this may cost employers thousands of dollars more each year [6][11]. Insomnia itself causes billions of dollars in damage and sleep disorders each year, which can lead to higher medical costs [11][22]. The onset of fatigue may be swift, or after weeks or months of 
manual labor it can be the result of accumulated effects. Factors taken into consideration in aviation industry in this respect are:

- Age: It is an important factor for age-related dynamic tasks. In the aviation industry, flight crews tend to fall asleep late with age. This is particularly common for male flying teams [3][55].

- Caffeine, nicotine, and alcohol: The effect of caffeine in many foods and beverages such as coffee, chocolate, tea, energy drinks vary from person to person. The effect of caffeine, which is known to have an effect on attention, is very effective for some, while for others it is negligible. Caffeine stimulates the brain. Alcohol makes you feel sleepy. Nicotine is a major factor in continuous attention [3][56].

- Sleep disorders: Sleep quality is an important factor affecting fatigue. Sleep disorder can contribute to the formation of fatigue. Flight crews are at special risk of sleep disorders due to shift work system [3][27].

- Environmental Factors: Many factors such as light, noise and resting areas affect sleep. Sleeping in the dark room is easier. Resting places are very important for flight crews. For example, radio stations around the hotel may cause noise, which may affect rest during a stay in a hotel after a flight [1][3].

\section{Fatigue risk management in aviation industry}

Air transport is a complex system that includes a complex, interconnected, distributed network of human operators, procedures and technological systems. Multiple causes of known and sometimes unknown risk factors related to aviation should be analyzed in an integrated systematic manner [37][38]. Flight and duty limitations and associated resolution conditions are traditional ways to manage fatigue. Conventional regulations do not take into account the interaction between sleep loss and circadian rhythms. New methods need to be developed to understand the causalities of the predecessors leading to serious events and accidents [3][40]. In ultra-secure systems such as commercial aviation operations, safety-critical errors and incidents are unpredictable, uncommon, and are not a source of routine monitoring data.

Fatigue Risk Management System (FRMS) is defined as data-driven and scientifically based, which identifies organizational procedures and procedures for controlling fatigue risk in aviation operations and enables continuous monitoring and management of safety risks associated with errors. In FRMS, they need to be analyzed to determine if flight crew fatigue is a contributing factor [3][53]. In the literature, flight fatigue is a significant and long-term problem in the aviation transport industry [54]. To minimize the effect of fatigue-related errors, a controller is made, and measurements are evaluated periodically [37].

\subsection{The principles for fatigue management}

For high-risk industries such as aeronautics and medicine, 24-hour uninterrupted work is mandatory in some cases where work is necessary, and these industries are known to carry higher safety risks associated with fatigue [15][16][26]. As mentioned in the 
ICAO definition, there are basic scientific principles to be considerable for fatigue management [3]:

\section{- Scientific principle 1: Sleep}

Fatigue is associated with lack of sleep or sleep deprivation [20][21]. It is known that good quality sleep has a significant impact on human health and employee performance depending on the amount of sleep, working hours and order. Especially shift workers are more vulnerable to performance and health effects such as sleep deprivation, misalignment of circadian rhythms [26][27]. According to neurophysiological conditions, there are two types of sleep: Rapid eye movement (REM) and Non-Rapid eye movement (NREM) [22].

$\checkmark \quad$ Rem: Rapid eye movement (REM) sleep accounts for approximately $25 \%$ of sleep time [24]. REM sleep is known to be associated with long-term apneas, hypopneas, and severe hypoxemia [25].

$\checkmark$ Non-Rem: Non-REM sleep is divided into three stages depending on the characteristics of brain waves. Stage 1 represents lighter sleep and occurs as the transition from burn to sleep.

This stage is generally the result of frequent arousal caused by sleep disorders such as sleep apnea, periodic movement in sleep, or snoring. Stage 2 is known as moderate sleep and dominates the sleep stages with $50 \%$ of the total sleep time. Stage 3, known as deep sleep, is called slow-wave sleep (SWS) [23][24].

\section{- Scientific principle 2: Sleep loss and recovery}

Effects such as cognitive reasoning, attention, memory and increased response time and error rates due to sleep deprivation pose a great risk especially for the aviation and medical sectors. Workers in the aviation industry are threatened by fatigue from sleep loss. Risks are greater both in terms of cost and in terms of passenger carrying capacity. The melting at the Three Mile Island nuclear power plant in 1979; The Chernobyl nuclear disaster in 1986; the 1986 explosion of the space shuttle Challenger; Exxon Valdez oil spill in 1989; Korea Air 801 is known to have been partly responsible for fatigue in major accident that killed more than 200 people in a 1997 crash. In these accidents, it is clear that determining the sleep requirement of employees can save people's lives and institutions can save money [22][28][29][30]. In the research of the 401 Army aviator and aircraft crew, $72 \%$ of the pilots reported that they flew under high numbness [32].

- Scientific principle 3: Circadian effects

The term "Circadian", introduced by Halberg in 1959, is a fluctuation controlled by the body's 24-hour biological clock [34]. It affects long working hours and circadian rhythms in aviation operations [35]. Circadian rhythm includes extensive body functions include body temperature, hormone secretion, digestion, physical and mental performance, mood and others [20][40]. The effects of Circadian rhythms, whose effects on alertness, 
physiology, and subjective fatigue experience are known to peak in the afternoon (day) and rise in the morning or early morning (at night) [20][33].

\section{- Scientific principle 4: Workload}

The International Air Transport Association (IATA) reveals that current trends in air transport can increase the number of passengers to 8.2 billion by 2037 . Many occupational groups in the aviation sector need long-term training. Therefore, the personnel working in the aviation industry are working overtime. Employees may feel tired due to the increased workload [4][36]. Fatigue, which adversely affects the probability of people producing safe performances and actions, has been found to be a contributing factor to accidents, injuries, and death [3][18][36]. ICAO defines workload as mental and physical activity. Employees tend to experience physical and mental fatigue due to irregular working hours, long flight times, pressure changes, and tasks that crewmembers must complete within a certain period of time [2][39].

\subsection{Fatigue management approaches for aviation cabin crew}

Fatigue management refers to methods by which Service Providers and operational personnel address the safety effects of fatigue. In general, FAA (Federal Aviation Administration), NTSB (National Transportation and Safety Board), ICAO Standards and Recommended Practices (SARPs) and care organizations support different approaches to identify and prove the role of fatigue in aviation incidents and accidents, for example: [2][4]

- First of all, the industry complies with the flight and duty time limits in accordance with the rules set by the regulator and manages fatigue hazards using existing Safety Management System (SMS) operations to identify other types of hazards and express risks

- Fatigue is defined as a legal hazard in the industry, a FRMS approved by the regulator is developed and implemented

- The flight crew is informed about this subject and related trainings are organized

- The effects can be measured by developing fatigue assessment techniques, and companies can perform cost-benefit analysis [3][4][44][45][46].

FRMS shares several main features for workers in relation to such strategies. Scientific approaches bolster operational experience. Fatigue management should have a shared responsibility among regulators, operators and crew [2][3].

Vigilance that affects physical, mental performance and social life should be examined in all aspects and conditions, and conditions can be provided for adequate sleep. Mental and physical activities and sleep management (falling asleep and dormancy) with circadian rhythm effect can be monitored [2][31][32][33]. Due to the fatigue of the workload, it can be monitored whether the employee has decreased in physical and mental performance. It can be expressed as the safety risk posed by team members due to fatigue [3][42][43][44]. 


\subsection{Fatigue assessment for cabin crew}

FRMS involves measuring the fatigue, sleep, alertness, performance and workload of the cabin crew. Performance, psychophysiological and subjective measurement techniques are used [44][45].

\subsubsection{Assessment methods}

Measuring and assessment fatigue is a complicated process. There is no single method for determining and measuring fatigue risk. Because there are many factors associated with fatigue, and furthermore, different ways to determine the effects of fatigue and to be evaluated alertness. Measurement tools can be divided into subjective and objective. A core set of measurement comprised of both mental and physical aspect can be selected for fatigue monitoring [21][44][45].

- Subjective measurement: Depending on the programs and operations, flight crews make reports about fatigue or fatigue related errors, incidents and accidents, and accordingly, reports can be transmitted through programs. The collected data are evaluated, and meaningful results are obtained.

$\checkmark$ Surveys or questionnaires for cabin crew

$\checkmark$ Transmission of fatigue by cabin crew fatigue reports

$\checkmark$ Determination of subjective fatigue and sleepiness levels (such as 'Karolinska sleepiness scale and Samn Perelli fatigue scale) $[2][21][46]$.

- Objective measurement: Performance and psychophysiological tests are applied to cabin crews to determine the risk associated with fatigue. Tests such as Psychomotor Vigilance Task (PVT), Multi-Attribute Test Battery (MATB), and Operator Vehicle Interface Task (OVI) are used to characterize fatigue [45]. The PVT test is a high-signal load response - time test that produces various performance measures against sleep deprivation. Firstly, the deceleration of sleep deprivation and sleep-related responses, PVT results by measuring the employee's contribution to work and task reveal the interaction with the circadian system and sleep processes [44][45][46][47][48][49].

\subsection{Modeling}

Organizations and regulators need the analysis of data to identify the root cause of fatigue. Because they follow a more sophisticated method to better define 24/7 uptime regulations (WTAs), potentially increase safety, reduce risk levels, and increase operational flexibility and efficiency. Various modeling methods are used for best results. Computer modeling can be used to monitor the effects of the flight crew and contribute to the changes in performance. There are following commercial biomathematical models (BMMs) used for fatigue sleep deprivation:

- $\quad$ Fatigue Avoidance Scheduling Tool (FAST)

- The Sleep, Activity, Fatigue and Task Effectiveness (SAFTE)

- $\quad$ Fatigue Index Tool (FIT)

- System for Aircrew Fatigue Evaluation (SAFE). 
For example, Fatigue Audit InterDyne (FAID) and System for Aircrew Fatigue Evaluation (SAFE) can provide insight into the way the sleep regulator works, depending on the duration of sleep and the time to start sleeping [47][48].

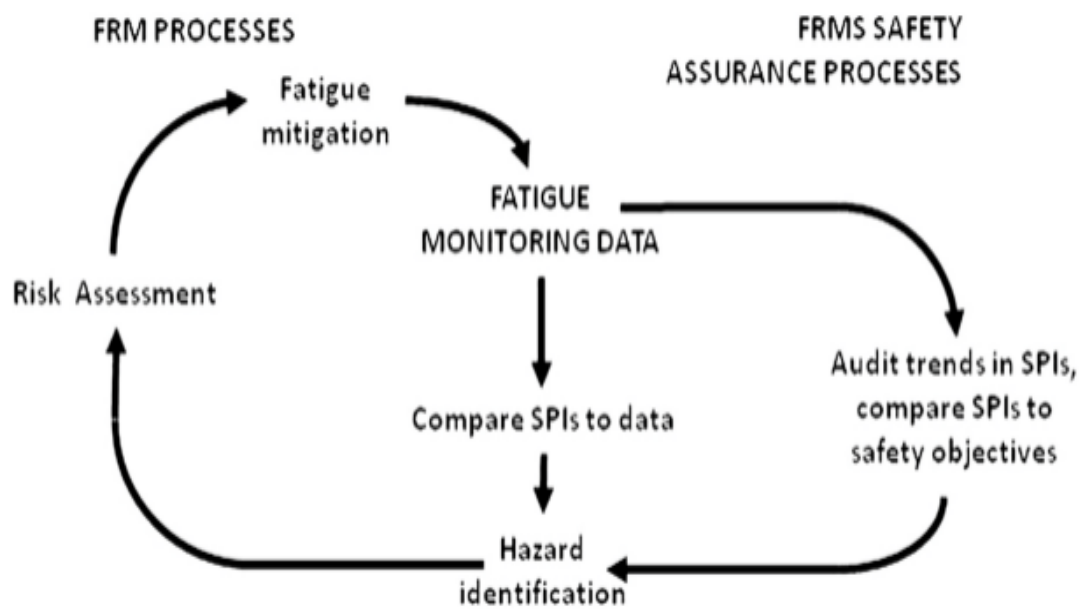

Figure 2: Analysis of fatigue [47]

\subsection{Fatigue risk management and mitigation}

Fatigue, seen as an increasing safety risk by the society, needs regulation by governments and operators. Rule-of-service hours (HOS) are one of the most common control processes, and due to the weak scientific support and less flexibility, a broader safety approach is emerging, the Safety Management System (SMS).The aerospace industry, which is at an important and critical level in terms of safety, imposes common safety responsibility for regulators, practitioners, and employees [2][50][51].

\begin{tabular}{|l|l|l|}
\hline \multicolumn{2}{|c}{ Challenges } & \multicolumn{2}{c|}{ Solutions } \\
\hline Industry Culture & 1 & Fatigue Education \\
\hline Fatigue Assessment & 2 & FRMS \\
\hline Scheduling Practices & 3 & Fatigue Research \\
\hline Government Inaction & 4 & Assessment \\
\hline Fatigue Education & 5 & Hours of Service Limits \\
\hline Work Life Balance & 6 & Safety Culture \\
\hline Fatigue Research & 7 & Collaboration \\
\hline Root Cause Analysis & 8 & Public Relations \\
\hline
\end{tabular}

Figure 3: Fatigue challenges and solutions [46] 


\subsection{Regulatory Responsibility and Industry Responsibility}

Regulatory means providing the frame; operators to manage fatigue risks that is responsible for achieving an acceptable applicable safety and security level. Operators are responsible for monitoring and managing fatigue hazards, providing fatigue management training, and planning and implementing cabin crews and pilots to perform their duties safely [50][51][52]. Operators should be responsible for:

- Making sure that cabin crews are informed and introduced about FRMS

- Creating an appropriate working environment

- Marking sure that roster of crew is based on international aviation organizations and civil aviation organization regulations

- Establishment of an appropriate reporting mechanism and encouraging flight crew to report on fatigue related issues such as not fit to fly, etc.

- Make sure that indicators for any exceedance are tracked via FRMS

- Making promotion and encouraging cabin crews to contribute to FRMS.

\section{Individual responsibility}

Cabin crews should be responsible for:

- Following the fatigue risk management policies determined by the industry and operator

- Determining sleep and rest management based on shift and duty duration,

- Participating in training and education related to fatigue risk management provided by the operator

- Reporting of any issues and occurrence related to fatigue via the company reporting system [3][4][50][51][52].

\subsection{Fatigue assessment systems and tools in aviation industry}

Following are few visual examples of tools and systems that are in current use in the aviation industry for fatigue assessment and analysis. Figure 4 is the representation of FAST interface taking into consideration the consequences of longer work hours against the amount of sleep, resulting in sleep deprivation and fatigue.

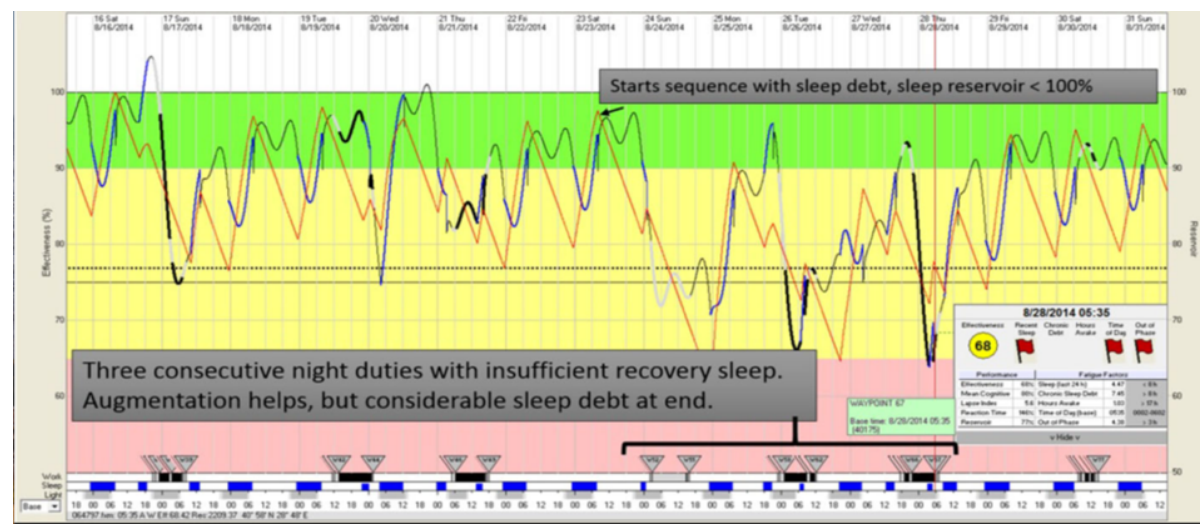

Figure 4: visual FAST interface [57] 
Figure 5 - similar to figure 4, represents fatigue assessment and avoidance by analyzing sleep patterns and showing when performance might be lower.

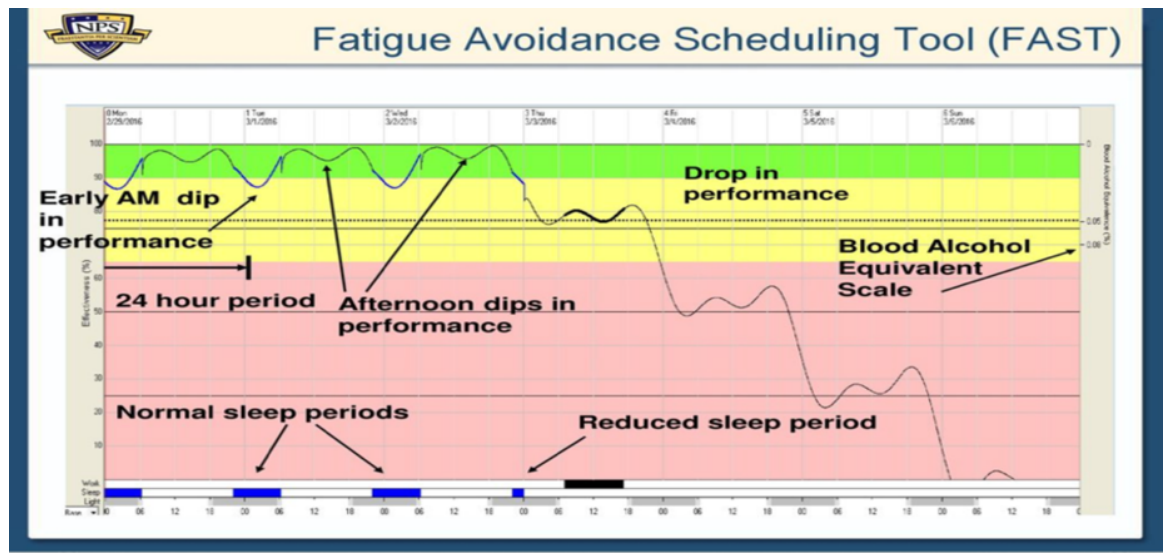

Figure 5: FAST system interface

Figure 6 - represents a fatigue calculator which helps to self-evaluate sleep fatigue level and counter measures for each level.

Figure 7 - an app available on store. This uses user input of work time and rest period to determine fatigue seriousness and respective counter measure.

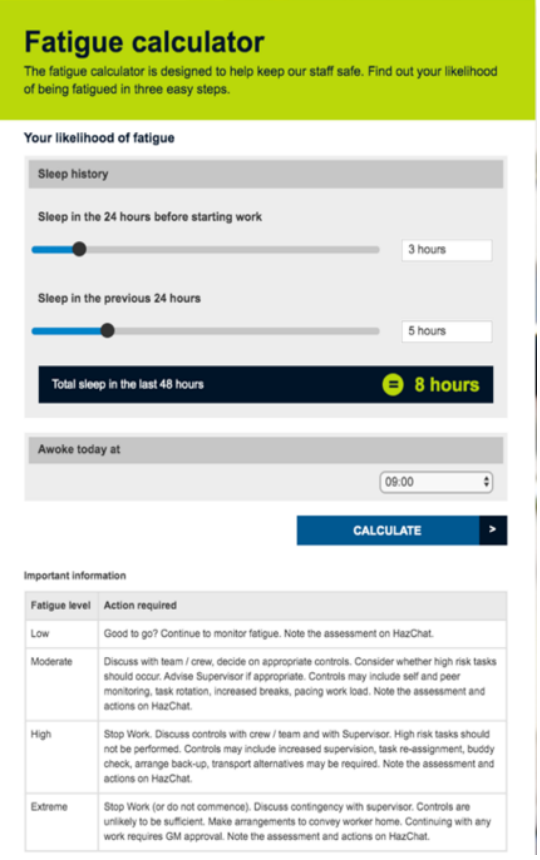

Figure 6: Fatigue Calculator by Energex [58]

\section{Flight Duty \& Rest Calculator}



Figure 7: Rest Calculator available on google play store 
Figure 8 - EU flight time calculator available on the app store. Similar to the Flight duty and rest calculator this app takes flight time and rest time as input to determine the level of fatigue and whether personnel are fit for duty.

Figure 9 - crew alert app available on app store takes in duty roster, sleep algorithm, time variation in different cities during travel as data to provide relevant analysis and result for crew members.

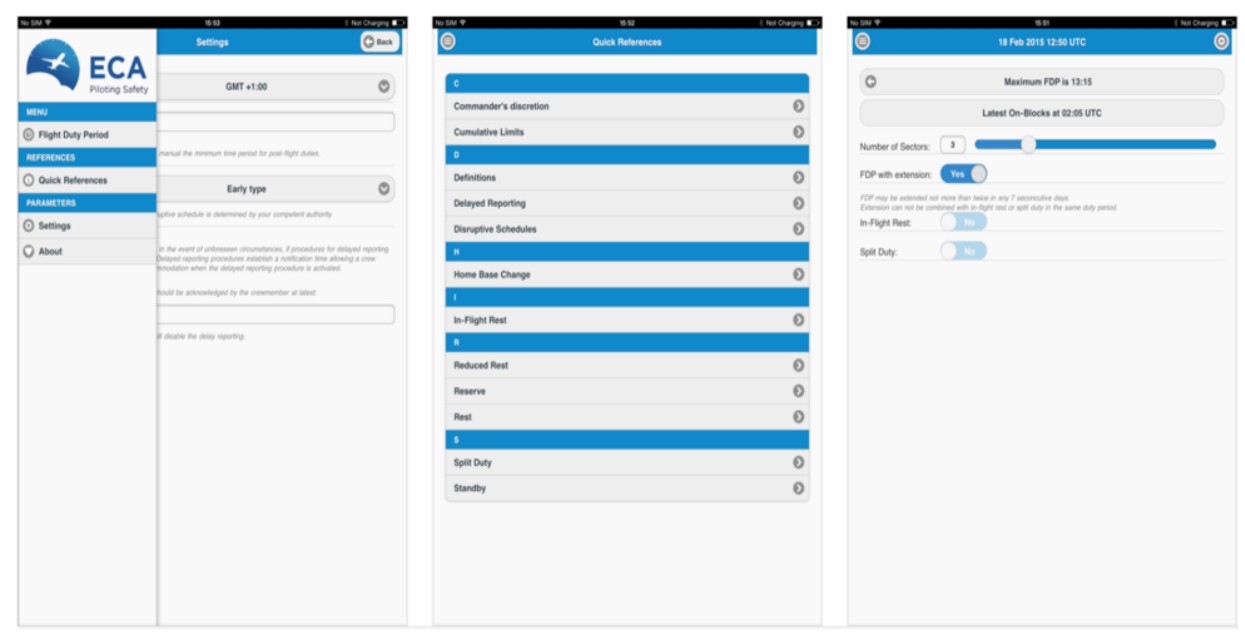

Figure 8: EU FLT Calculator, Available on apple app store
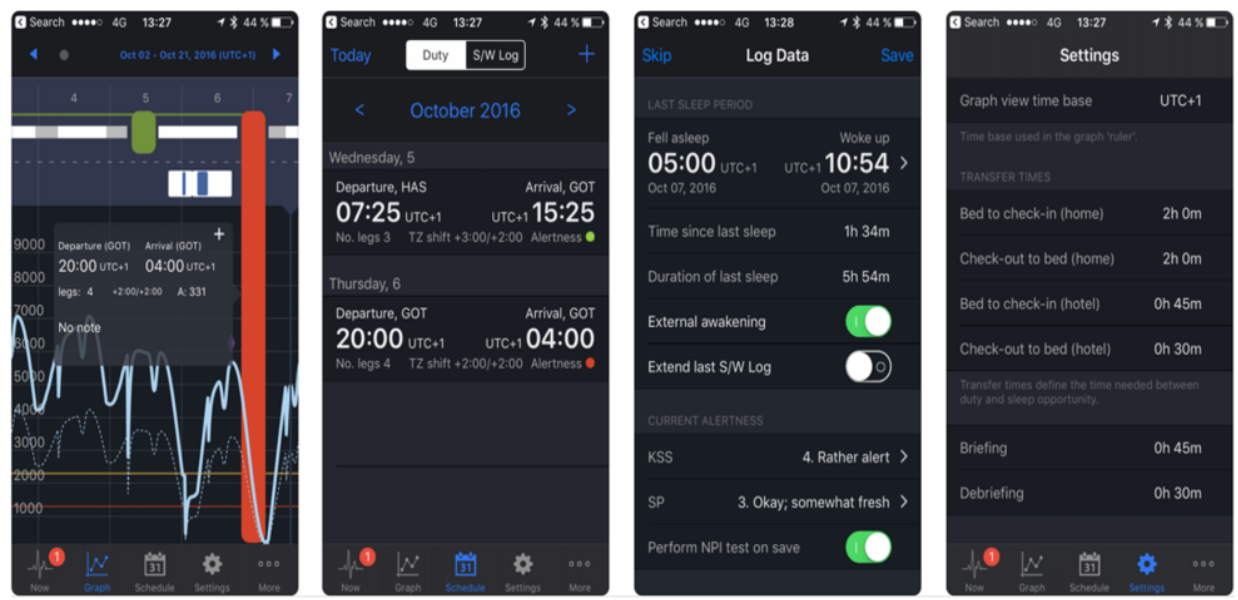

Figure 9: Crew Alert lite app on Apple app 
Table 1. Fatigue Measurement Map

\begin{tabular}{|c|c|c|c|c|c|c|}
\hline $\begin{array}{l}\text { Fatigue } \\
\text { Categories }\end{array}$ & $\begin{array}{l}\text { HOW: Influencing } \\
\text { Factors }\end{array}$ & WHICH: Symptoms & $\begin{array}{l}\text { WHEN: Indicators of } \\
\text { Cabin Crew }\end{array}$ & WHAT: To Measure & WHAT: Data needed & WHAT: Technologies/tools available \\
\hline \multirow{5}{*}{ Lifestyle } & regular alcohol use & drowsy eyes, tiredness & less attentive & $\begin{array}{c}\text { high blood pressure, irregular } \\
\text { heartbeat }\end{array}$ & $\begin{array}{c}\text { blood sample, urine sample, } \\
\text { breath analysis }\end{array}$ & $\begin{array}{c}\text { use of breathalysers, urine and blood } \\
\text { test }\end{array}$ \\
\hline & lack of physical activity & quick tiredness, physical pain & Quick exhaustion & $\begin{array}{l}\text { muscular tension, } \\
\text { breathlessness }\end{array}$ & $\begin{array}{l}\text { electrical synapsis of the } \\
\text { nerves }\end{array}$ & $\begin{array}{l}\text { motor and sensory reflex test of } \\
\text { muscles, self-reports }\end{array}$ \\
\hline & emotional stress & mood swings, unstable mood & emotional breakdown & $\begin{array}{l}\text { irregular brain/nerval } \\
\text { activity }\end{array}$ & heart rate, breathing interval & $\begin{array}{l}\text { different PDAs, use of ECG (electro } \\
\text { cardio graph) }\end{array}$ \\
\hline & overweight & body structure change, & $\begin{array}{c}\text { prone to diseases, self- } \\
\text { loathing }\end{array}$ & $\begin{array}{c}\text { standard mass index to } \\
\text { current state }\end{array}$ & body weight, height & BMI (Body Mass Index) \\
\hline & physical exertion & tiredness, low interest & $\begin{array}{l}\text { less attentive, quick } \\
\text { exhaustion }\end{array}$ & $\begin{array}{l}\text { self-report, other medical } \\
\text { factors as heart rate, } \\
\text { breathing status }\end{array}$ & $\begin{array}{l}\text { electrical synapsis of the } \\
\text { nerves, tension in muscles } \\
\text { and ligaments }\end{array}$ & $\begin{array}{l}\text { motor and sensory reflex test of } \\
\text { muscles, self-reports }\end{array}$ \\
\hline \multirow{5}{*}{$\begin{array}{l}\text { Physical Health } \\
\text { conditions }\end{array}$} & anaemia & pale skin, insomnia, dizziness & tiredness, less attentive, & $\begin{array}{l}\text { haemoglobin and iron count } \\
\text { in blood }\end{array}$ & $\begin{array}{l}\text { haemoglobin count, mean } \\
\text { corpuscular volume, iron } \\
\text { count }\end{array}$ & $\mathrm{CBC}$ (complete blood count) test \\
\hline & arthritis & $\begin{array}{l}\text { decreased range of motion, } \\
\text { pain, stiffness }\end{array}$ & $\begin{array}{l}\text { functionality, job duties } \\
\text { hinderance, tiredness }\end{array}$ & $\begin{array}{c}\begin{array}{c}\text { swollenness of joints, loss of } \\
\text { motion, blood test }\end{array} \\
\end{array}$ & $\begin{array}{c}\text { physical deformity, motion } \\
\text { data, blood test data }\end{array}$ & physical examination, $\mathrm{x}$-ray, blood test \\
\hline & eating disorder & rapid weight loss/gain, & $\begin{array}{l}\text { prone to diseases, issues } \\
\text { with self }\end{array}$ & $\begin{array}{c}\text { eating attitude test, other } \\
\text { psychological behaviour and } \\
\text { tests }\end{array}$ & $\begin{array}{l}\text { height, weight, heart rate, } \\
\text { blood pressure, data on skin } \\
\text { and nails }\end{array}$ & $\begin{array}{l}\text { Rating of Anorexia and Bulimia } \\
\text { (RAB) test, psychological aptitude test }\end{array}$ \\
\hline & diabetic & $\begin{array}{l}\text { frequent urination, blurry } \\
\text { vision, extreme fatigue }\end{array}$ & prone to other diseases, & $\begin{array}{l}\text { sugar level in blood, glucose } \\
\text { tolerance }\end{array}$ & $\begin{array}{l}\text { glucose and sugar level, } \\
\text { BMI (body mass index) }\end{array}$ & $\begin{array}{l}\text { blood test for sugar and glucose level, } \\
\text { Glycated haemoglobin (A1C) test, }\end{array}$ \\
\hline & allergies & $\begin{array}{l}\text { rashes, irritation, shortness of } \\
\text { breath }\end{array}$ & $\begin{array}{c}\text { transferrable, causes } \\
\text { hindrance in duties and work } \\
\text { area }\end{array}$ & skin test, blood test & $\begin{array}{l}\text { IgE (immunoglobulin E test) } \\
\text { level, antibody count in } \\
\text { body }\end{array}$ & blood and skin test \\
\hline \multirow{3}{*}{ Mental Issue } & anxiety & $\begin{array}{c}\text { nervousness, hyperventilation, } \\
\text { weakness }\end{array}$ & $\begin{array}{l}\text { tiredness, breathlessness, } \\
\text { emotional instability }\end{array}$ & $\begin{array}{c}\text { self-report, psychometric } \\
\text { data }\end{array}$ & $\begin{array}{c}\text { reports, Q\&A, } \\
\text { characteristics of patients }\end{array}$ & $\begin{array}{l}\text { mental and physical test, blood and } \\
\text { urine test, behavioural aptitude test }\end{array}$ \\
\hline & depression & fatigue, melancholy, sadness & $\begin{array}{l}\text { emotional instability, trust } \\
\text { issue }\end{array}$ & $\begin{array}{l}\text { self-report, psychometric } \\
\text { data }\end{array}$ & $\begin{array}{l}\text { primary care/physician data, } \\
\text { medications in use }\end{array}$ & $\begin{array}{c}\text { mental/physical test, blood/ urine test, } \\
\text { behavioural aptitude test }\end{array}$ \\
\hline & Medication & nausea, upset stomach & various & contents of medication & prescriptions, dosage of use & standard dosage Vs prescribed dosage \\
\hline
\end{tabular}




\section{Fatigue Measurement Concept Map}

Software development is a complex enduvear. When modeling for future business needs, the model that best meets the needs and is suitable for time and budget constraints is selected. Two situations are important when developing a process model: current state and future state. It is vital to determine the scope of the model. A detailed measurement fatigue map is made as the first step to define the limits of the concepts to be modeled. Table 1 provides a comprehensive measurement map of fatigue including factors, symptoms, risks posed on cabin crew, measuring technique, data needed for measurement. It has been developed using the $\mathrm{W}^{*} \mathrm{H}$ model. Another important step is to create a change management process on how to move from the current state to the future state. [59][60][61][62][63][64][65][66][67][68][69][70][71][75][76].

\subsection{Process model for fatigue measurement}

The process model is a simplified view of the events with details. The organization is expanded by detailing the layer by layer until the details are at the desired level. It is expected that the current difficulties will be well understood and the model to be designed will overcome these difficulties. Business process modeling is useful for defining, analyzing and demonstrating the desired processes of the operational performance of tasks. From various tools that are available to model business processes, Bizagi Modeler is selected for this study [71[75].

A process model has been created in order to find out under which conditions fatigue occurs. Additionally, the process also helps to determine the risk level of fatigue, to reveal what are the available measurements, and to identify various strategies and methods to mitigate risks if needed. The most important factor in this process model is the selection of the appropriate measurement method

Process view: BizAgi Process Modeler (www.bizagi.com) is used for graphic representation of the workflow process. BizAgi Modeler provides fast process automation thanks to its graphical and dynamic environment. BizAgi Process Modeler is a program that allows you to create work flow diagrams (schemes) that allow you to increase your productivity. BizAgi supports the entire business process lifecycle through different components. It provides many operations such as compliance with Business Process Model and Notation (BPMN) standards, opening to teamwork, and previewing the schema process with its simulation feature [72][75].

There is no single measurement method for measuring fatigue. In order to perform fatigue measurements of the flight crew, objective tests are planned based on performance tests and physical impressions. As shown in Figure 10, this process is divided into three different levels. At each level, it is to be designed as to include different devices and techniques to gather performance data with regards to assigned tasks and to transmit the data to the next level or to create a direct output process. An example of such a sub process view is illustrated in Figure 11. 




Figure 10: BPMN diagram representing FRMS assessment methods

Data sources are needed for FRMS monitoring. Intelligent devices and medical proficiency testing can be used for this purpose. In the first stage, it is aimed to be able to track the data via mobile applications and wearable watches, during and after the flight. Wearable technology, which is expressed for all kinds of objects containing the technology we wear, is an intelligent machine with computing capabilities. Wearable technology incorporating electronic components such as sensors, cameras, microphones and keyboards has an important field of applications in many sectors [73]. Smart watches are expected to become even more popular in the near future. With the new features expected in smartwatches, personalized data can be transformed into a reliable clinical tool for improved health monitoring. Heart rate, blood oxygenation, deep sleep monitoring and reflex measurement can be done with smart devices and applications. In the second stage, medical proficiency tests such as blood test, urine test and height-weight index can be applied from the periodic mandatory medical tests of the cabin crew [17][74].

In the second stage, it is planned to make measurements of medical proficiency tests such as blood test, urine test and height-weight index and to access the recorded data as needed. Figure 12 presents the comprehensive fatigue risk assessment methodology and the system to be supported in the future for aviation cabin crews. 


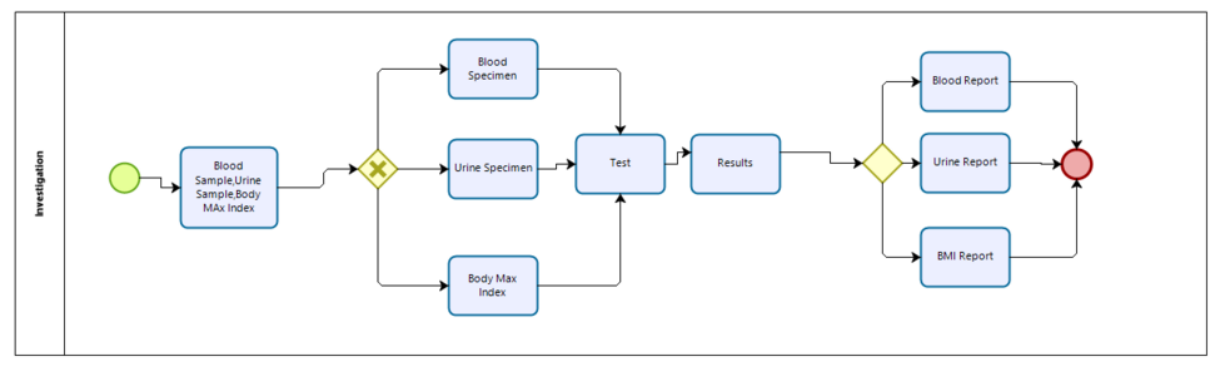

Figure 11: BPMN diagram representing Sub-Process

Risk management is one of the pillars of safety management systems. Data collection and analysis are important for assessing the risk of fatigue. In Figure 12, a comprehensive fatigue risk assessment methodology is proposed, combining datadriven analysis and assessment techniques. There are three main parts of this methodology: collecting various information and data, evaluating the results and calculating the risk value.

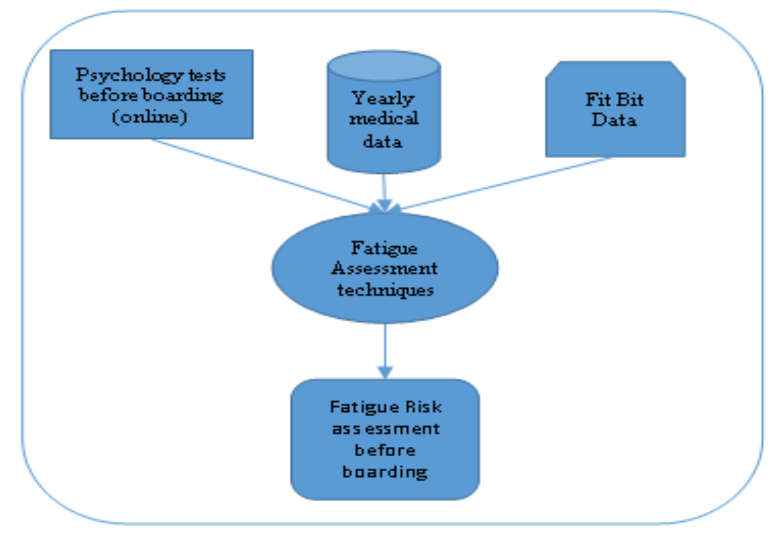

Figure 12: A Comprehensive fatigue risk assessment methodology

\section{Conclusion}

Safety plays an important role in the aviation world. In relation to this, airlines need a safety management system. Fatigue is a big problem for the flight crew. There are many factors that cause fatigue and fatigue symptoms vary. Fatigue risk assessment and management is not addressed in a comprehensive manner for cabin crew members.

In this study, firstly, the definition of fatigue is explained, and related concepts are clarified. Factors affecting fatigue, types of fatigue, causes of fatigue, why fatigue risk management is needed, methods of measuring fatigue, and the responsibilities of institutions and employees to reduce fatigue risk are discussed. 
According to the explored researches there is no comprehensive and integrated mechanism which comprise physical, psychological and social parameters to determine cabin crew's fatigue level. Therefore, a concept map is created to reach a comprehensive risk assessment tool. While creating the workflow chart, wearable technology will be provided to the cabin crew team to access real-time information of the personnel to realize their organized functions and to obtain reliable data. In the future this technology will be developed to ensure that all data is accurate and that the measurements are saved for reducing the risks of fatigue with acceptable objective measurements.

In summary, this study has provided the first step towards achieving a major contribution to flight safety for designing feedback and measuring mechanisms, In the future research a risk assessment method will be designed and implemented as a mobile app for a comprehensive fatigue risk assessment system and steps to improve fatigue risk management of aviation cabin crew.

\section{References}

[1] Sadeghniiat-Haghighi, Khosro, and Zohreh Yazdi. "Fatigue Management in the Workplace." Industrial Psychiatry Journal 24, no. 1 (2015): 12-17.

[2] ICAO. Doc 9966 Manual for the Oversight of Fatigue Management Approaches- Second Edition (2016).

[3] Fatigue Management Guide for Airline Operators 2nd edition 2015.

[4] Cabon, Philippe, Stephane Deharvengt, Jean Yves Grau, Nicolas Maille, Ion Berechet, and Régis Mollard. "Research and Guidelines for Implementing Fatigue Risk Management Systems for the French Regional Airlines." Accident Analysis and Prevention 45, no. sS (2012): 41-44.

[5] Yen, Jin-Ru, Chiung-Chi Hsu, Hsuan Yang, and Hero Ho. "An Investigation of Fatigue Issues on Different Flight Operations." Journal of Air Transport Management 15, no. 5 (2009): 236-240.

[6] Caldwell, John A. "Fatigue in Aviation." Travel Medicine and Infectious Disease 3, no. 2 (2005): 85-96.

[7] Lee, Seungyoung, and Jin Ki Kim. "Factors Contributing to the Risk of Airline Pilot Fatigue." Journal of Air Transport Management 67 (2018): 197-207.

[8] Li, Wei. "A cabin crew fatigue risk comprehensive evaluation model." 12th International Conference on Fuzzy Systems and Knowledge Discovery (FSKD), Zhangjiajie. (2015). pp. 1596-1600.

[9] Boksem, Maarten A.S, and Mattie Tops. "Mental Fatigue: Costs and Benefits." Brain Research Reviews 59, no. 1 (2008): 125-139.

[10] Boksem, Maarten A.S, Theo F. Meijman, and Monicque M. Lorist. "Mental Fatigue, Motivation and Action Monitoring." Biological Psychology 72, no. 2 (2006): 123-132

[11] Caldwell, John A. "The Impact of Fatigue in Air Medical and Other Types of Operations: A Review of Fatigue Facts and Potential Countermeasures.” Air Medical Journal 20.1 (2001): 25-32.

[12] Marcora, Samuele M., Walter Staiano, and Victoria Manning. "Mental Fatigue Impairs Physical Performance in Humans." Journal of Applied Physiology (Bethesda, Md. : 1985) 106, no. 3 (2009): 857.

[13] Williamson, Richard J et al. "The Relationship of Fatigue to Mental and Physical Health in a Community Sample.” Social Psychiatry and Psychiatric Epidemiology 40.2 (2005): 126-132.

[14] Shen, Jianhua, Joseph Barbera, and Colin M Shapiro. "Distinguishing Sleepiness and Fatigue: Focus on Definition and Measurement." Sleep medicine reviews 10.1 (2006): 63-76.

[15] Ventikos, N. P., Lykos, G. V., \& Vagias, N. A." Human Fatigue: Evaluation with the Usage of Bayesian Networks." In Computational Intelligence Systems in Industrial Engineering, no. 6 (2012): 651-676.

[16] Thomas, Matthew J. W.; Ferguson, Sally A.” Aviation, Space, and Environmental Medicine." Aerospace Medical Association, no. 2 (2010): 665-670.

[17] Godfrey, A., Hetherington, V., Shum, H., Bonato, P., Lovell, N. \& Stuart, S. (2018). "From A to Z: Wearable Technology Explained." Maturitas 113: 40-47

[18] Mitler, M.M., M.A Carskadon, C.A Czeisler, W.C Dement, D.F Dinges, and R.C Graeber. "Catastrophes, Sleep, and Public Policy: Consensus Report." Sleep 11, no. 1 (1988): 100-109.

[19] Chang, Yu-Hern, Hui-Hua Yang, and Wan-Jou Hsu. "Effects of Work Shifts on Fatigue Levels of Air Traffic Controllers." Journal of Air Transport Management 76 (2019): 1-9. 
[20] Goel, Namni et al. "Circadian rhythms, sleep deprivation, and human performance." Progress in molecular biology and translational science vol. 119 (2013): 155-90.

[21] Goker, Zeynep. "Fatigue in The Aviation: An Overview of The Measurements and Countermeasures." (2018).

[22] "Sleep Disorders and Sleep Deprivation; an Unmet Public Health Problem." 1 Dec. 2006: n. pag.

[23] Cai, Zi-Jian. "The Functions of Sleep: Further Analysis." Physiology \& Behavior 50, no. 1 (1991): 5360.

[24] Javaheri, Sogol, and Susan Redline. "Sleep, Slow-Wave Sleep, and Blood Pressure." Current Hypertension Reports 14, no. 5 (2012): 442-448.

[25] Shrivastava, Deepak, Syung Jung, Mohsen Saadat, Roopa Sirohi, and Keri Crewson. "How to Interpret the Results of a Sleep Study." Journal of Community Hospital Internal Medicine Perspectives 4, no. 5 (2014).

[26] Akerstedt, Torbjörn, and Kenneth P Wright Jr. "Sleep Loss and Fatigue in Shift Work and Shift Work Disorder." Sleep medicine clinics vol. 4,2 (2009): 257-271.

[27] Kolla, Bp, and Rr Auger. "Jet Lag and Shift Work Sleep Disorders: How to Help Reset the Internal Clock." Cleveland Clinic Journal of Medicine 78, no. 10 (2011): 675-684.

[28] Smith A.P., Allen P., Wadsworth E.J., "Seafarers"e fatigue: the Cardiff Research Programme". Report to MCA and HSE. (2006)..

[29] Caldwell, John A. "Crew Schedules, Sleep Deprivation, and Aviation Performance." Current Directions in Psychological Science 21, no. 2 (2012): 85-89.

[30] Tarman, D. [Recent Evidence on Fatigue and Sleep Deprivation in Both the Medical and Military Aviation Professions]. 2013.

[31] Owens, Rachel. "The Science of Sleep." Library Journal 143, no. 14 (2018): 28.

[32] Tran, Tuan, Kimberly R. Raddatz, Elizabeth T. Cady, Bradford Amstutz, Pete D. Elgin, Christopher Vowels, and Gerald Deehan. "Effects of Extreme Sleep Deprivation on Human Performance." Idaho Academy of Science Symposium and Meeting,University Place, Idaho Falls, ID 2007.

[33] Caldwell, J., and S. Gilreath. "A Survey of Aircrew Fatigue in a Sample of U.S. Army Aviation Personnel." Aviation, Space, and Environmental Medicine 73, no. 5 (2002): 472-480

[34] Arendt, J., S. Deacon, J. English, S. Hampton, and L. Morgan. "Melatonin and Adjustment to Phase Shift." Journal Of Sleep Research 4 (1995): 74-79.

[35] McCallum, M., Sanquist, T., \& Mitler, M.” Commercial Transportation Operator Fatigue Management Reference." U.S. Department of Transportation Research and Special Programs Administration., (2003).

[36] van ngelen, Alwin et al. "Risk Factors for Fatigue Among Airline Pilots." International archives of occupational and environmental health 90.1 (2017): 39-47

[37] Caldwell, John A., J. Lynn Caldwell, Lauren A. Thompson, and Harris R. Lieberman. "Fatigue and Its Management in the Workplace." Neuroscience and Biobehavioral Reviews 96, no. C (2019): 272-289.

[38] Luxhoj, J. T., \&amp; Coit, D. W.” Modeling low probability/high consequence events: anaviation safety risk model. In RAMS\&\#39;06." Annual Reliability and Maintainability Symposium, (2006). 215 221.

[39] Netjasov, Fedja, and Milan Janic. "A Review of Research on Risk and Safety Modelling in Civil Aviation." Journal of Air Transport Management 14, no. 4 (2008): 213-220.

[40] Armentrout, Jeffrey J., Dwight A. Holland, Kevin J. O'Toole, and William R. Ercoline. "Fatigue and Related Human Factors in the Near Crash of a Large Military Aircraft." Aviation, Space, and Environmental Medicine 77, no. 9 (2006): 963.

[41] Miyagi, M." Serious Accidents and Human Factors - Breaking the Chain of Events Leading to an Accident: Lessons Learned from the Aviation Industry." Reston, VA: AIAA, (2005)

[42] Samel, Alexander, R. Curtis Graeber, David F. Dinges, and Mark R. Rosekind. Principles and Guidelines for Duty and Rest Scheduling in Commercial Aviation - NASA/TM-1996-110404. 1996.

[43] Wesensten, Nancy Jo, Gregory Belenky, David R. Thorne, Mary A. Kautz, and Thomas J. Balkin. "Modafinil Vs. Caffeine: Effects on Fatigue During Sleep Deprivation." Aviation, Space, and Environmental Medicine 75, no. 6 (2004): 520.

[44] Mehta, Ranjana, and Michael Agnew. "Influence of Mental Workload on Muscle Endurance, Fatigue, and Recovery During Intermittent Static Work." European Journal of Applied Physiology 112, no. 8 (2012): 2891-2902.

[45] Wilson, G.F., J.A Caldwell, and C.A Russell. "Performance and Psychophysiological Measures of Fatigue Effects On Aviation Related Tasks of Varying Difficulty." International Journal of Aviation Psychology 17, no. 2 (2007): 219-247.

[46] Avers, Katrina E., William B. Johnson, Joy O. Banks, Darin Nei, and Elizabeth Hensley. Fatigue Solutions for Maintenance: From Science to Workplace Reality. 2011. 
[47] Gander, Philippa H., Jim Mangie, Margo J. Van Den Berg, A Alexander T. Smith, Hannah M. Mulrine, and T Leigh Signal. "Crew Fatigue Safety Performance Indicators for Fatigue Risk Management Systems." Aviation, Space, and Environmental Medicine 85, no. 2 (2014): 139.

[48] Dawson, Drew, Y. Ian Noy, Mikko Härmä, Torbjorn Åkerstedt, and Gregory Belenky. "Modelling Fatigue and the Use of Fatigue Models in Work Settings." Accident Analysis and Prevention 43, no. 2 (2011): 549-564.

[49] Dawson, Drew, David Darwent, and Gregory D. Roach. "How Should a Bio-mathematical Model Be Used Within a Fatigue Risk Management System to Determine Whether or Not a Working Time Arrangement Is Safe?" Accident Analysis and Prevention 99, no. Pt B (2017): 469-473.

[50] Honn, Kimberly A., Brieann C. Satterfield, Peter Mccauley, J. Lynn Caldwell, and Hans P.A Van Dongen. "Fatiguing Effect of Multiple Take-offs and Landings in Regional Airline Operations." Accident Analysis and Prevention 86, no. C (2016): 199-208.

[51] Dawson, Drew, and Kirsty Mcculloch. "Managing Fatigue: It's About Sleep." Sleep Medicine Reviews 9, no. 5 (2005): 365-380.

[52] Gander, P., L. Hartley, D. Powell, P. Cabon, E. Hitchcock, A. Mills, and S. Popkin. "Fatigue Risk Management: Organizational Factors at the Regulatory and Industry/company Level." Accident Analysis And Prevention 43, no. 2 (2011): 573-590.

[53] Gander, Philippa H., Hannah M. Mulrine, Margo J. Berg, A. Alexander T. Smith, T. Leigh Signal, Lora J. Wu, and Gregory Belenky. "Effects of Sleep/wake History and Circadian Phase on Proposed Pilot Fatigue Safety Performance Indicators." Journal of Sleep Research 24, no. 1 (2015): 110-119.

[54] Lei, W., and S. Ruishan. "Analysis on Flight Fatigue Risk and the Systematic Solution." Lecture Notes in Computer Science (including Subseries Lecture Notes in Artificial Intelligence and Lecture Notes in Bioinformatics) 6779 (2011): 88-96.

[55] Avin, Keith G., and Laura a Frey Law. "Age-related Differences in Muscle Fatigue Vary by Contraction Type: A Meta-analysis." Physical Therapy 91, no. 8 (2011): 1153.

[56] Moore, David J., Edmund Keogh, and Christopher Eccleston. "Identifying Experimental Methods to Determine the Effect of Pain on Attention: A Review of Pain, Caffeine, Alcohol and Nicotine Studies." Human Psychopharmacology: Clinical and Experimental 24, no. 8 (2009): 601-618.

[57] Saftefast.com. (2019). SAFTE-FAST | FRMS | SAFTE-FAST CONSOLE. [online] Available at: https://www.saftefast.com/frms-visual-fast.html [Accessed 8 Nov. 2019].

[58] Energex.com.au. (2019). Fatigue Calculator - Energex. [online] Available at: https://www.energex.com.au/home/fatigue-calculator [Accessed 9 Nov. 2019].

[59] Shattuck, N. (2017). Scheduling Sleep: A Clear Mind, A Combat Edge.

[60] Zhu, Y., R.R Jankay, L.C Pieratt, and R.K Mehta. "Wearable Sensors and Their Metrics for Measuring Comprehensive Occupational Fatigue: A Scoping Review." Proceedings of the Human Factors and Ergonomics Society 61, no. 1 (2017): 1041-1045.

[61] Gleaves, David H., Crystal A. Pearson, Suman Ambwani, and Leslie C. Morey. "Measuring Eating Disorder Attitudes and Behaviors: A Reliability Generalization Study." Journal of Eating Disorders 2, no. 1 (2014): 6.

[62] Julian, Laura J. "Measures of Anxiety: State-Trait Anxiety Inventory (STAI), Beck Anxiety Inventory (BAI), and Hospital Anxiety and Depression Scale-Anxiety (HADS-A." Arthritis Care \& Research 63, no. S11 (2011): S467-S472.

[63] Garner, D M., P E. Garfinkel, and D P. Bonato. "Body Image Measurement in Eating Disorders." Advances in Psychosomatic Medicine 17 (1987): 119.

[64] Nevonen, Lauri, Anders G. Broberg, David Clinton, and Claes Norring. "A Measure for the Assessment of Eating Disorders: Reliability and Validity Studies of the Rating of Anorexia and Bulimia Interview Revised Version (RAB-R." Scandinavian Journal of Psychology 44, no. 4 (2003): 303-310.

[65] Mayoclinic.org. (n.d.). Allergy skin tests - Mayo Clinic. [online] Available at: https://www.mayoclinic.org/tests-procedures/allergy-tests/about/pac-20392895 [Accessed 16 Nov. 2019].

[66] Mayoclinic.org. (n.d.). Diabetes - Diagnosis and treatment - Mayo Clinic. [online] Available at: https://www.mayoclinic.org/diseases-conditions/diabetes/diagnosis-treatment/drc20371451\#: :targetText=A\%20fasting\%20blood\%20sugar\%20level\%20from $\% 20100 \% 20$ to\%20125\% 20mg,blood\%20sugar\%20level\%20is\%20measured. [Accessed 17 Nov. 2019].

[67] Mieli.fi. (n.d.). Depression | The Finnish Association for Mental Health. [online] Available at: https://mieli.fi/en/home/mental-health/mental-disorders/depression [Accessed 17 Nov. 2019].

[68] Spettell, Claire M., Terry C. Wall, Jeroan Allison, Jaimee Calhoun, Richard Kobylinski, Rachel Fargason, and Catarina I. Kiefe. "Identifying Physician-Recognized Depression from Administrative Data: Consequences for Quality Measurement." Health Services Research 38, no. 4 (2003): 1081-1102. 
[69] Sylvia, Louisa G., Emily E. Bernstein, Jane L. Hubbard, Leigh Keating, and Ellen J. Anderson. "Practical Guide to Measuring Physical Activity." Journal of the Academy of Nutrition and Dietetics 114, no. 2 (2014): 199-208.

[70] Thalheim, B., and A. Dahanayake. "A Conceptual Model for Services." Lecture Notes in Computer Science (including Subseries Lecture Notes in Artificial Intelligence and Lecture Notes in Bioinformatics) 9382 (2015): 51-61

[71] Nurcan, Selmin, Anne Etien, Rim Kaabi, Iyad Zoukar, and Colette Rolland. "A Strategy Driven Business Process Modelling Approach." Business Process Management Journal 11, no. 6 (2005): 628649.

[72] Garcia, F., A. Vizcaino, and C. Ebert. "Software Technology Process Management Tools." Ieee Software 28, no. 2 (2011): 15-18.

[73] Park, Yong, and Marko Skoric. "Personalized Ad in Your Google Glass? Wearable Technology, Hands-Off Data Collection, and New Policy Imperative." Journal of Business Ethics 142, no. 1 (2017): 71-82.

[74] Quesada-González, Daniel, and Arben Merkoçi. "Mobile Phone-based Biosensing: An Emerging "diagnostic and Communication" Technology." Biosensors and Bioelectronics 92 (2017): 549-562.

[75] Garcia, Felix, Aurora Vizcaino, and Christof Ebert. "Process Management Tools." IEEE Software 28, no. 2 (2011): 15-18.

[76] Chinosi, Michele, and Alberto Trombetta. "BPMN: An Introduction to the Standard." Computer Standards \& Interfaces 34, no. 1 (2012): 124-134 